\title{
The effect of dietary sodium bicarbonate on performance and blood parameters of broiler chickens and local Balady breed inoculated with Salmonella gallinarum ${ }^{*}$
}

\author{
H.A. Zakaria ${ }^{1,3}$, M.J. Tabbaa ${ }^{1}$, K.M. Alshawabkeh ${ }^{1}$ and K. Altaif ${ }^{2}$ \\ ${ }^{1}$ The University of Jordan, Department of Animal Production, Faculty of Agriculture \\ Amman -11942, Jordan \\ ${ }^{2}$ Al Hussein Bin Talal University, Department of Biology, Faculty of Sciences \\ P.O.Box (20), Amman -11821, Jordan
}

(Received 30 June 2008; revised version 3 December 2008; accepted 20 March 2009)

\begin{abstract}
To determine the role of $0.5 \%$ sodium bicarbonate $\left(\mathrm{NaHCO}_{3}\right)$ on the performance of chickens inoculated with Salmonella gallinarum, a total of 720 one-day-old-broiler chicks from four strains Hubbard (H), Lohmann (L), Ross (R) and Balady (B) were grown for 42 days in 24 pens, two levels of $\mathrm{NaHCO}_{3}(0$ and $0.5 \%)$ and 3 replicates/treatment $(4$ strains $\times 2$ dietary treatment $\times 3$ replicates of 30 birds for each group) in a completely randomized design. Dietary $\mathrm{NaHCO}_{3}$ supplementation had significant adverse effects on average body weight $(\mathrm{P}<0.001)$, feed intake and feed conversion ratio (FCR). Body weight of the four non-treated groups was significantly higher than treated $(\mathrm{P}<0.001)$ and $\mathrm{B}$ strain birds had the lightest final body weight and the poorest FCR and was significantly different from the 3 commercial strains $(\mathrm{P}<0.05)$. Blood glucose, cholesterol, and total protein were not affected by dietary alterations or strain differences. The re-isolation of Salmonella gallinarum from liver and intestine of sacrificed and inoculated chickens revealed that the organism could be shed from liver and intestine with alternative rates in all strains. There was a significantly higher mortality rate in treated groups $(\mathrm{P}<0.05)$ during the whole experimental period. Furthermore, $\mathrm{B}$ strain was numerically the most resistant to Salmonella gallinarum of the untreated groups. The use of $0.5 \%$ dietary $\mathrm{NaHCO}_{3}$ did not improve the performance of the different strains nor prevent the localization of Salomenella gallinarum.
\end{abstract}

KEY WORDS: Salmonalla gallinarum, Balady, sodium bicarbonate, growth performance, chickens

\footnotetext{
* Supported by the Deanship of Academic Research at the University of Jordan

${ }^{3}$ Corresponding author: e-mail: zakariah@ju.edu.jo
} 